\title{
The Apple Falls Increasingly Far: Parent-Child Correlation in Schooling and the Growth of Post- Secondary Education in Switzerland
}

\author{
Alejandra Cattaneo $^{\mathrm{a}}$, Sandra Hanslin ${ }^{\mathrm{b}}$ and Rainer Winkelmann ${ }^{\mathrm{b}, \mathrm{c}}$
}

JEL Classification: I21, J62

Keywords: Intergenerational mobility, tertiary education

\section{Introduction}

If one studies how patterns of education in the Swiss population evolved over the last half century or beyond, two observations stand out. First, there is a persistent general trend towards more formal education. For example, the proportion of people with just mandatory schooling decreased from 29.7 percent for those born in the 1940's (and thus educated in the 1940's and 1950's) to 17.7 percent for those born in the 1970's. 'Secondly, women caught up strongly. Comparing the proportion of university graduates in the two cohorts 1940-49 and 196069, there was a 2.2 percentage point increase for men but a 4.5 percentage point increase for women. ${ }^{2}$ Indeed, in 2002, women were overrepresented among those completing the university entrance qualification (Matura), and at a rate of 47 percent only slightly underrepresented among those entering university (VELLACOTT and Wolter, 2004, p.40). These developments are of course in no way unique to Switzerland. Qualitatively similar trends can be observed in many countries.

a Swiss Co-ordination Centre for Research in Education

b University of Zurich, Socioeconomic Institute

c Address for correspondence: University of Zurich, Socioeconomic Institute, Zürichbergstr. 14, CH-8032 Zürich, Switzerland, phone: +41 (0)4463422 92, fax: +41 (0)44634 4996 , email: cattaneo@sts.uzh.ch, sandra.hanslin@wwi.uzh.ch,winkelmann@sts.uzh.ch. We thank two anonymous referees for valuable comments.

1 Source: Swiss Census 2000; own calculations.

2 The 2000 Census data underestimate the university graduation rate for 1970-79 cohort substantially, as the youngest members were just 21 in 2000 and could not have completed their education by that time. In order to avoid such truncation effects, we classify in the following analysis those born between 1964 to 1973 as our most recent cohort. 
One can think of many potential explanations. Some are linked to labor market developments where skill biased technical change and globalization have increased the skill premia in wages, and made the position of low skilled domestic workers increasingly precarious. Or education may simply be a normal (or even superior) good the demand for which increases with rising income levels. In either case, the government certainly has responded by increasing expenditures in the education sector substantially. Moreover, anti-discrimination legislation and changes in social norms and values have increased female participation above the general trend.

Against this general background, the specific goal of our paper is to investigate how parental education has interacted with the trend, i.e., how the intergenerational transmission in education levels has evolved over time. Clearly, at any point in time, it is well documented that parental education is a main predictor of own education: the higher the education of the parents, the better - on average - the performance in school and the higher the education of the offspring. ${ }^{3}$ Several issues surrounding this intergenerational transmission have been studied in detail, such as how institutional aspects of the school system might reinforce or weaken the transmission, ${ }^{4}$ or whether the observed association is due to genetic factors, environmental correlates of parental education, or causally related to parental education per se.

What is less common, however, is research into trends in intergenerational education mobility over time. For Switzerland, to the best of our knowledge, no such an analysis has been undertaken yet, although it touches upon the central social policy concern of equity in education. Who has been affected most by the expansion of the upper-secondary and tertiary education sectors? Have some socio-economic strata benefited more than others? And if so, has the trend been one towards more or less equality in access and outcomes? These are questions of obvious interest for social and education policy.

One possible reason why the evolution of intergenerational education mobility in Switzerland over time has not yet been systematically studied may have to do

3 For Switzerland, see for example BaUer and RipHahn (2006a) and the references provided in Vellacott and Wolters (2004); international references include Cameron and Heckman (2001), Ermisch and Francesconi (2001), Dustmann (2004), and Woessmann (2004).

4 See Schütz, Ursprung and Woessmann (2004) and Bauer and Riphahn (2006b) for studies showing that early tracking in school actually makes the link stronger.

5 Recent contributions to this nature vs. nurture debate include BEHRMAN and RosenZweig (2002) and Antonovics and Goldberger (2005). Black, Devereux and Salvanes (2005) find little evidence for a causal relationship between parent education and child education, using a natural experiment in Norway. 
with the scarcity of suitable data. Essentially, one needs survey information where direct parental background questions are included for each person, regardless of age. While the Census does not provide such information, a recent relatively large representative household survey - the Swiss Household Panel (SHP) - does. For our empirical analysis, we use data from six waves (1999-2004) of the SHP and concentrate on the comparison of four birth cohorts of individuals born between 1934 and 1973, capturing the trends in education over three decades.

Formally, we proceed in two steps. First, we develop a framework in which the contrast in education participation between birth cohorts can be decomposed into a parental background effect and a general expansion effect. The parental background effect arises since even for constant intergenerational mobility rates (i.e., without any behavioral changes), an exogenous increase in parental education will lead to more educated children (because more educated parents tend to have more educated children), who in turn will have more educated children and so forth. As the analysis shows, the contribution of this effect to overall growth in education is larger for men than for women. For women, 62 percent of the trend growth in higher education can be explained by increased transition rates. Since rates increased most for the lower education strata, there is a trend towards increased mobility and equity.

The second step is then to extend the analysis to a multivariate framework, where we use logit models in an attempt to separate the relative contributions of the mother's education, the father's education, and the financial situation during childhood. We would like to answer two questions: (a) What role does the financial channel play in the intergenerational transmission of education; and (b) Has the importance of this channel changed over time?

The data unfortunately provide only very indirect information on the past financial well-being of the family, namely a self-report on "financial problems during youth" (yes/no). This is a soft indicator prone to substantial misreporting. With this caveat in mind, we find that although the number of individuals reporting financial problems during youth has declined over time, there is some evidence that such problems have actually become more important as an impediment for higher education. The convergence in education by parental background persists once we control for financial problems, and is therefore likely related to factors outside of the financial domain. In general, the changes over time are not measured with sufficient precision to reject the null hypothesis of no change. For this reason, and because of the imperfect nature of our financial indicator, the results should be thus interpreted cautiously. 


\section{Trends in Education in Switzerland}

The trends we review in this section relate to the enrolment rates in the different schooling options over time. The education system per se has stayed remarkably resilient over time, and it can, at a useful level of generality, be described as a four-part system: compulsory schooling only, upper secondary schooling, advanced vocational training and academic tertiary training.

Children start with primary school at the age of six or seven. ${ }^{6}$ Primary school lasts for six years. It is followed by three years of lower secondary school ("Sekundarstufe I"). Primary school and lower secondary school together complete the compulsory education. After lower secondary school, at the age of 15 to 16 , the pupils can either attend a full time vocational school, start an apprenticeship, both for periods of between two to four years, or they can continue their general education (mostly gymnasium) for three to four years. The majority chooses the apprenticeship system which prepares for a vocational career. The gymnasium prepares students to enrol at university. By the age of 18 or 19 a typical individual has finished either gymnasium or an apprenticeship. Further tertiary level education is offered by universities, the Federal Institute of Technology, universities of applied sciences and a variety of advanced vocational degree programs.

In the following we distinguish between two types of tertiary education, academic tertiary education or vocational tertiary training. Thus, we study the following four levels of educational attainment, in ascending order:

1. No completed compulsory school, completed compulsory school, domestic science course, one year school of commerce

2. Upper secondary school: general training school, apprenticeship, full time vocational school, gymnasium

3. Vocational tertiary level: advanced vocational degree programs

4. Academic tertiary level: universities and universities of applied science.

Figures 1 and 2 show the population shares for these four schooling levels over time, i.e., for successive birth cohorts from 1900 up to 1975 . The information comes from the Swiss Census of 2000. We show the graphs separately for men and women, allowing for gender differences in schooling. Consider first the

6 Children typically can enter primary school in the fall of the year in which they complete their sixth birth year by April 30. Here and elsewhere, there is some variation across the 26 cantons (or states) that make up Switzerland, since the education system is a cantonal responsibility. We refer to the predominant rules. 
Figure 1: Highest Education Level by Birth Cohort, Swiss Men

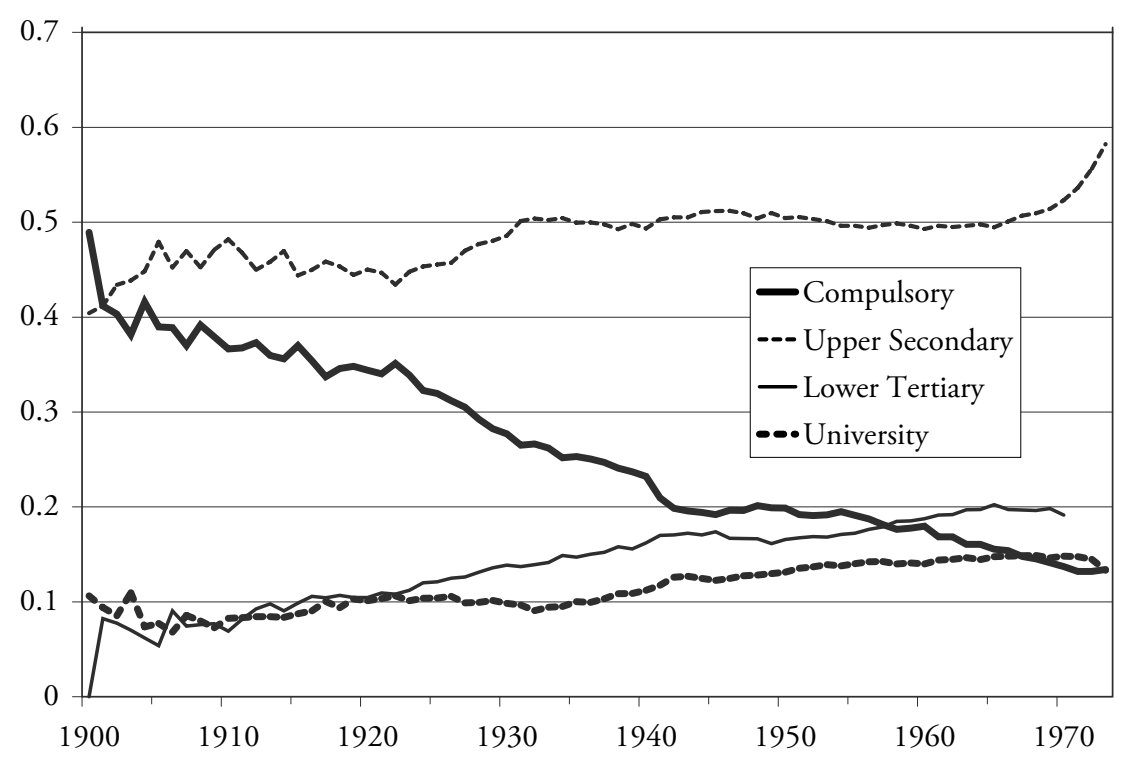

Figure 2: Highest Education Level by Birth Cohort, Swiss Women

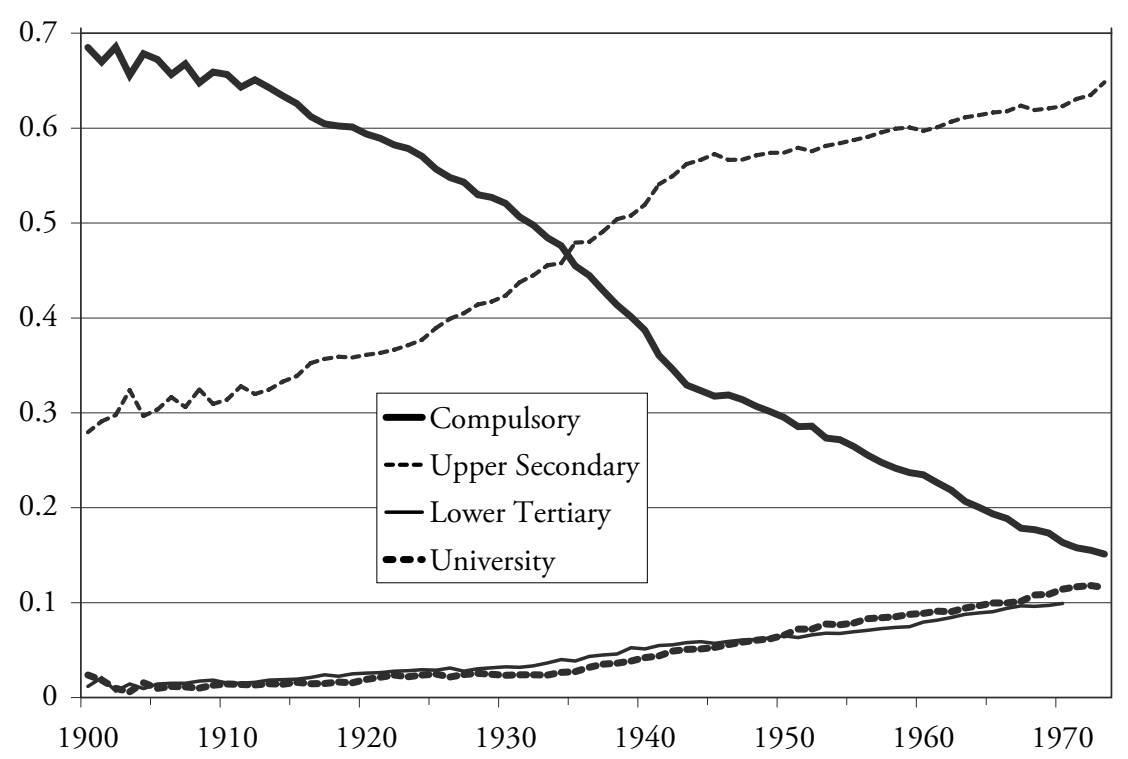

Both Figures: Source: Swiss Census 2000 
results for men in Figure 1. We find the aforementioned steady decline in the proportion of men with just compulsory education. The share of both types of tertiary education increases over time, university education in particular starting with the 1935 cohort (i.e., in the mid 1950's). On the other hand, the proportion of men with upper secondary education, the leading category in all years, does not change much from the 1935 cohort onwards, hovering at a level of just under 50 percent. We also observe that at the end of the observation window, i.e., for those born in the early 1970s, there is a notable increase at the upper secondary level, coupled with a decrease at the tertiary level. The likely explanation is that not all men have completed their highest degree at the age of 25 . This problem points to a general limitation of cohort studies of this type. Trends in education are only recorded with a relatively long time lag, and little can be said about the behavior of those who are currently making their education choices.

Figure 2 shows the female population shares over time. The trends are qualitatively the same as those for men, only that they are more accentuated. In a nutshell, the early cohort of women participated much less in advanced education programs than did their contemporary men. By the end of the observation period, the female-male education gap had narrowed substantially, but it hadn't vanished entirely. The proportion of women with just compulsory schooling decreased from above 70 percent to about 17 percent, only a couple of percentage points above the male rate. Among women with any post-secondary qualification, the split between academic and vocational tertiary education was almost even over most of the period, whereas more men attended vocational tertiary education programs than academic ones.

\section{The Data}

Since the census data do not provide information on parental background and education - except for the relatively small subgroup of young persons still living at home that is studied by BAUER and RipHAHN (2006a) - we have to base our investigation on an alternative data source. We use data from the first six (19992004) waves of the Swiss Household Panel (SHP), an annual survey of a random sample of households in Switzerland (Zimmermann et al. 2003). Since the SHP collects information not only on individuals' but also on parents' characteristics, it is possible to analyze trends in the inter-generational transmission of education using information on all persons that are included in the data at least once. Since for adult people, own and parental education are largely time invariant, using repeated observations on the same person brings no particular advantage. The 
benefit in using all six waves of data is rather that it adds to the number of observations, since, for various reasons, new individuals join the sample over time.

\begin{tabular}{|c|c|c|c|}
\hline & Total & Women & Men \\
\hline 1999 & 5,356 & 2,964 & 2,392 \\
\hline 2000 & 48 & 21 & 27 \\
\hline 2001 & 38 & 20 & 18 \\
\hline 2002 & 24 & 18 & 6 \\
\hline 2003 & 26 & 12 & 14 \\
\hline 2004 & 3,977 & 2,166 & 1,811 \\
\hline Total & 9,469 & 5,201 & 4,268 \\
\hline
\end{tabular}

As seen in Table 1, there were 5,356 valid observations (for people born between 1934 and 1973) in the first year of the survey. The next four years of data add only relatively few observations, whereas a large refreshment sample in 2004, linked to the integration of the SILC survey (Survey of Income and Living Conditions) into the SHP, adds another 3,977 cases. Thus, our analysis is based on a total of 9,469 cases, 5,201 of which are for women and 4,268 for men.

Since the main focus is on the change of determinants of education, we group the data into four consecutive birth cohorts of ten years length each. The first and oldest cohort contains individuals born between 1934 and 1943. Due to the increasing mortality we disregard individuals born before 1934, and thus older than 65 in 1999. The fourth and youngest cohort comprises individuals born between 1964 and 1973. We are interested in the individual's highest educational attainment and we work on the assumption that most of the individuals who attain a tertiary education quite straightforwardly have finished their schooling at the age of 26 . $^{7}$ Observations with no information about own and both parents' education are dropped. The cohort sizes are given in the first column of Table 2. The first cohort consists of 801 women and 668 men, whereas the fourth cohort is about twice that size.

7 For observations from 2004, the requirement is of course less stringent. Those born in 1973 are already 31 by then. 
Table 2: Distribution of Education Levels by Sex and Cohort

\begin{tabular}{lccccc}
\hline & $\begin{array}{c}\text { Number of } \\
\text { Observations }\end{array}$ & $\begin{array}{c}\text { Compulsory } \\
\text { Education }\end{array}$ & $\begin{array}{c}\text { Upper } \\
\text { Secondary }\end{array}$ & $\begin{array}{c}\text { Advanced } \\
\text { vocational }\end{array}$ & $\begin{array}{c}\text { Academic } \\
\text { degree }\end{array}$ \\
\hline Females & & & & & \\
Cohort 1934-1943 & 801 & 0.32 & 0.55 & 0.04 & 0.09 \\
Cohort 1944-1953 & 1252 & 0.25 & 0.58 & 0.05 & 0.12 \\
Cohort 1954-1963 & 1615 & 0.17 & 0.63 & 0.07 & 0.14 \\
Cohort 1964-1973 & 1533 & 0.12 & 0.61 & 0.07 & 0.20 \\
\hline Males & & & & & \\
Cohort 1934-1943 & 668 & 0.12 & 0.47 & 0.15 & 0.26 \\
Cohort 1944-1953 & 1001 & 0.08 & 0.51 & 0.15 & 0.26 \\
Cohort 1954-1963 & 1361 & 0.07 & 0.50 & 0.17 & 0.26 \\
Cohort 1964-1973 & 1238 & 0.06 & 0.46 & 0.16 & 0.32 \\
\hline
\end{tabular}

Source: Swiss Household Panel 1999-2004.

The original variable about individual's and parents' highest completed educational attainment in the SHP-data has eleven outcomes. These categories were recoded into the four categories mentioned in Section 2, in order to get a clear ordinal structure and to avoid outcomes with a small number of observations. An exception is the education of the mother, where we distinguish only between three educational outcomes. The two educational outcomes "Advanced vocational training" and "Academic degree" are combined into a single outcome "Any tertiary" because the proportion of mothers with academic degrees is very low for the first cohorts.

Unfortunately, the data do not contain information on the family income at the time of the individual's youth. But there is an item in the SHP questionnaire which refers to the financial situation of the family when the individual was young. The question is: "During your youth, did your family encounter serious financial problems?" The variable financial problems is a dummy variable which is equal to one if the family encountered financial problems and zero if not.

We start the descriptive data analysis by affirming that the population trends found in the census data are similarly observed in our sample survey data. Table 2 shows the highest qualification by cohort. The fraction of women with academic degrees has more than doubled from the 34-43 to the 64-73 cohort, from 9 to 20 percent, and for men the corresponding increase was from 26 to 32 percent. While the female increase is about evenly spread over the 4 cohorts, the male increase is entirely attributable to the last cohort. There appears to be some over- 
reporting of academic degrees in the SHP, relative to the census figure (or, possibly, an over-representation of highly educated people). This aspect of the data may be of some concern and warrants further investigation. However, it is less of a problem for our study, since we are interested in changes rather than levels. Such changes are also evident for the fraction of the lowest educational attainment, which has decreased sharply by 20 percentage points (from 32 to 12 percent) for women and by 6 percentage points (from 12 to 6 percent) for men. The data provide thus evidence for increased education levels and for convergence between females and males education outcomes.

Table 3 provides sample means for other variables used in the analysis, again stratified by cohort. First, we find that education levels of parents show a pattern similar to that of children. The fraction of less educated parents decreases while the fraction of highly educated parents increases over time, when moving from the earlier cohorts to the later cohorts. Moreover, education levels of parents, who on average are about by 30 years older than their offspring, are lower overall. In theory, we might expect that the education distribution of parents of the 64-73 cohort is roughly similar to the offspring distribution of the 34-43 cohort. This is not quite the case in our data. For example, 45 percent of mothers of the 64-73 cohort in the data have compulsory education only, compared to 32 percent of women in the 34-43 cohort. Thus, there seems to be some underreporting of parental degrees, which could lead to a slight overestimation of the inter-generational upward mobility in education.

While 43 percent of individuals born between 1934 and 1943 indicate having grown up in a family with financial problems, this fraction decreased substantially over time. In the last cohort, the fraction of individuals who reported to have had financial problems in youth is only 16 percent. Table 3 includes two additional variables employed in the later analysis, siblings, a dummy variable which is equal to one if the individual has siblings and zero otherwise, as well as a dummy variable for living with both parents at the age of 16 . The variable siblings may be of interest if there is a quantity-quality tradeoff. The argument is that with more siblings, the resources invested by parents in the education of each single child are diminished, making it less likely that higher education levels are attained, ceteris paribus. ${ }^{8}$ Similarly, not living with both parents may be an indicator of a disadvantaged childhood. Again, educational outcomes may be diminished as a result. We see from Table 3, that both variables show rela-

8 Recent work by ANgrist, Levy and Schlosser (2006) cast however doubt on the causal nature of this quantity-quality trade-off. 
Table 3: Sample Means of the Explanatory Variables by Cohort

\begin{tabular}{lcccc}
\hline & $1934-1943$ & $1944-1953$ & $1954-1963$ & $1964-1973$ \\
\hline Mother: Compulsory school & 0.67 & 0.62 & 0.56 & 0.45 \\
Mother: Upper secondary school & 0.30 & 0.35 & 0.40 & 0.48 \\
Mother: Any tertiary education* & 0.03 & 0.03 & 0.03 & 0.06 \\
Father: Compulsory school & 0.37 & 0.36 & 0.30 & 0.23 \\
Father: Upper secondary school & 0.47 & 0.46 & 0.51 & 0.52 \\
Father: Advanced vocational training & 0.07 & 0.07 & 0.08 & 0.09 \\
Father: Academic degree & 0.08 & 0.11 & 0.11 & 0.16 \\
Financial problems & 0.43 & 0.29 & 0.23 & 0.16 \\
Siblings & 0.85 & 0.86 & 0.88 & 0.85 \\
Living with both parents & 0.87 & 0.90 & 0.91 & 0.88 \\
Swiss & 0.91 & 0.92 & 0.88 & 0.82 \\
\hline Observations & 1469 & 2253 & 2976 & 2771 \\
\hline
\end{tabular}

Swiss Household Panel 1999-2004.

* Due to small case numbers, the categories "Advanced vocational training" and "Academic degree" are combined into the single category "Any tertiary education" for mothers.

tively little variation across the cohorts. Thus, while these variables may explain cross-section variation in outcomes at a given point in time, they won't be able to explain trends in education.

There is some variation in the composition of the sample by citizenship, as the proportion of non-citizens has doubled from 9 percent for those born between 1934 and 1943 to 18 percent for those born between 1964-1973.

\section{The Importance of Parental Background: First Evidence}

As we have seen in the previous section, there is a striking downward trend in the proportion of people with low education, and upward trend in the proportion of people with an academic degree, in particular for women. This leads us to the central question of this paper: how much does own education depend on 
parental education, and how has this intergenerational transmission changed over time, if any. In other words, have all social levels benefited from the increase in higher education or has this increase benefited mostly individuals with highly educated parents?

Parents' abilities and education influence the highest schooling level of their offspring through a number of different channels. ${ }^{9}$ On one hand children inherit the genetically determined abilities of their parents which may result in similar school attainment. On the other hand more educated parents' may attach a higher importance to education and therefore invest more time and money in their children's education. In addition, they tend to have higher income and fewer children, both factors leading to higher available resources per child.

A simple descriptive framework for analyzing the relationship between parent and child education is provided by tabulations of conditional relative frequencies. There are potentially many ways to structure such tabulations. We could look at each child outcome, for each cohort, gender, and separately for mother's and father's education. Instead, we opt for a more focused analysis that in our view captures well the essence of the intergenerational transmission argument, namely the frequency of children with an academic degree, conditional on father's education, separately for men and women, for the first 1934-43 cohort and the youngest 1964-73 cohort. We look at the first and the last cohort since this allows us to investigate longer term trends over more than a generation. It is clear from Table 3 that the changes happened gradually, and using the middle cohorts would not change the qualitative results, only their magnitude.

The first panel of Table 4 shows the results for females, the second panel those for males. We know from Table 2, that only 9 percent of all women of the earlier 1934-43 cohort had acquired a tertiary academic degree. We now see that this aggregate number hides an enormous disparity by parental background. For women with a "compulsory only" father, the estimated probability (i.e., relative frequency) of an academic degree is 3.6 percent. For women with a "academic degree" father, the estimated probability of an academic degree rises to 50.9 percent. The difference in the estimated probability of an academic degree when moving from the lowest to the highest father's degree is thus a staggering 47.3 percentage points. Large differences are also observed for the 1964-73 female cohort (a 40.2 percentage gap), and for men in both cohorts.

9 For a review of the literature on the determinants of educational attainment see Haveman and Wolfe (1995). 
Table 4: Relative Frequency of Academic Degree by Father's Education for the 34-43 and 64-73 Cohorts

\begin{tabular}{|c|c|c|c|c|c|c|}
\hline & $P_{t-1}\left(A C \mid F E_{j}\right)$ & $P_{t}\left(A C \mid F E_{j}\right)$ & $\begin{array}{c}P_{t-1}\left(A C \mid F E_{j}\right)- \\
\quad P_{t}\left(A C \mid F E_{j}\right)\end{array}$ & $P_{t-1}\left(F E_{j}\right)$ & $P_{t}\left(F E_{j}\right)$ & $\begin{array}{c}P_{t-1}\left(F E_{j}\right)- \\
P_{t}\left(F E_{j}\right)\end{array}$ \\
\hline \multicolumn{7}{|c|}{ Females } \\
\hline$j=1$ & $\begin{array}{c}0.036 \\
(0.013)\end{array}$ & $\begin{array}{c}0.099 \\
(0.016)\end{array}$ & $\begin{array}{c}0.063 \\
(0.021)\end{array}$ & $\begin{array}{c}0.378 \\
(0.017)\end{array}$ & $\begin{array}{c}0.241 \\
(0.011)\end{array}$ & $\begin{array}{c}-0.137 \\
(0.023)\end{array}$ \\
\hline$j=2$ & $\begin{array}{c}0.072 \\
(0.013)\end{array}$ & $\begin{array}{c}0.154 \\
(0.014)\end{array}$ & $\begin{array}{c}0.082 \\
(0.019)\end{array}$ & $\begin{array}{c}0.477 \\
(0.016)\end{array}$ & $\begin{array}{c}0.517 \\
(0.013)\end{array}$ & $\begin{array}{c}0.040 \\
(0.022)\end{array}$ \\
\hline$j=3$ & $\begin{array}{c}0.101 \\
(0.034)\end{array}$ & $\begin{array}{c}0.202 \\
(0.035)\end{array}$ & $\begin{array}{c}0.094 \\
(0.050)\end{array}$ & $\begin{array}{c}0.080 \\
(0.009)\end{array}$ & $\begin{array}{c}0.080 \\
(0.007)\end{array}$ & $\begin{array}{c}-0.0002 \\
(0.013)\end{array}$ \\
\hline$j=4$ & $\begin{array}{c}0.509 \\
(0.059)\end{array}$ & $\begin{array}{c}0.502 \\
(0.032)\end{array}$ & $\begin{array}{r}-0.007 \\
(0.067)\end{array}$ & $\begin{array}{c}0.065 \\
(0.009)\end{array}$ & $\begin{array}{r}0.162 \\
(0.88)\end{array}$ & $\begin{array}{c}0.097 \\
(0.012)\end{array}$ \\
\hline \multicolumn{7}{|c|}{ Males } \\
\hline$j=1$ & $\begin{array}{c}0.120 \\
(0.021)\end{array}$ & $\begin{array}{c}0.176 \\
(0.023)\end{array}$ & $\begin{array}{c}0.056 \\
(0.035)\end{array}$ & $\begin{array}{c}0.369 \\
(0.018)\end{array}$ & $\begin{array}{c}0.222 \\
(0.013)\end{array}$ & $\begin{array}{c}-0.147 \\
(0.021)\end{array}$ \\
\hline$j=2$ & $\begin{array}{c}0.277 \\
(0.024)\end{array}$ & $\begin{array}{c}0.289 \\
(0.018)\end{array}$ & $\begin{array}{c}0.012 \\
(0.030)\end{array}$ & $\begin{array}{c}0.457 \\
(0.017)\end{array}$ & $\begin{array}{c}0.522 \\
(0.014)\end{array}$ & $\begin{array}{c}0.065 \\
(0.020)\end{array}$ \\
\hline$j=3$ & $\begin{array}{c}0.196 \\
(0.066)\end{array}$ & $\begin{array}{c}0.362 \\
(0.043)\end{array}$ & $\begin{array}{c}0.166 \\
(0.081)\end{array}$ & $\begin{array}{c}0.068 \\
(0.010)\end{array}$ & $\begin{array}{c}0.104 \\
(0.007)\end{array}$ & $\begin{array}{c}0.036 \\
(0.013)\end{array}$ \\
\hline$j=4$ & $\begin{array}{c}0.694 \\
(0.053)\end{array}$ & $\begin{array}{c}0.623 \\
(0.037)\end{array}$ & $\begin{array}{c}-0.071 \\
(0.065)\end{array}$ & $\begin{array}{c}0.106 \\
(0.013)\end{array}$ & $\begin{array}{c}0.153 \\
(0.010)\end{array}$ & $\begin{array}{c}0.047 \\
(0.016)\end{array}$ \\
\hline
\end{tabular}

$t-1$ : Cohort 1934-1943, $t$ : Cohort 1964-1973

Standard errors in parentheses.

\section{Decomposing the Trend Growth in Tertiary Degrees}

Given the large correlation between parental and own education, the long-term trends in education must be self-perpetuating to some degree: if more educated parents tend to have more educated children, then an exogenous increase in parental education will lead to more educated children, who will tend to have more educated children, and so forth. We refer to this automatism as parental background effect. An alternative explanation for the increased participation in higher education is that transition rates have increased per se. 
The probability of an academic degree $P_{t}(A C)$ at time $t$ can be decomposed in the following way

$$
P_{t}(A C)=\sum_{j=1}^{4} P_{t}\left(A C, F E_{j}\right)=\sum_{j=1}^{4} P_{t}\left(A C \mid F E_{j}\right) P_{t}\left(F E_{j}\right),
$$

where $F E_{j}, j=1, \ldots, 4$, refers to a father with educational attainment equal to $j=1, \ldots, 4$ as described in chapter 2 . Thus, the probability at any point in time depends both on the conditional transition rates $P_{t}\left(A C \mid F E_{j}\right)$ as well as on the marginal distribution of the fathers' education $P_{t}\left(F E_{j}\right)$. The change in the proportion of individuals with academic degrees can be a consequence of a change in the distribution of the father's education $P_{t}\left(F E_{j}\right)$, or that of a change in the conditional distribution $P_{t}\left(A C \mid F E_{j}\right)$. Let the subscript $t-1$ refer to the cohort 1934-1943, and the subscript $t$ refer to the cohort 1964-1973. We obtain the following decomposition of the between-cohort change:

$$
\begin{aligned}
\Delta P(A C):= & P_{t}(A C)-P_{t-1}(A C) \\
= & \sum_{j=1}^{4} P_{t}\left(A C \mid F E_{j}\right) P_{t}\left(F E_{j}\right) \\
& \quad-\sum_{j=1}^{4} P_{t-1}\left(A C \mid F E_{j}\right) P_{t-1}\left(F E_{j}\right) \\
= & \sum_{j=1}^{4}\left[P_{t}\left(A C \mid F E_{j}\right)-P_{t-1}\left(A C \mid F E_{j}\right)\right] P_{t}\left(F E_{j}\right) \\
& -\sum_{j=1}^{4}\left[P_{t}\left(F E_{j}\right)-P_{t-1}\left(F E_{j}\right)\right] P_{t-1}\left(A C \mid F E_{j}\right) \\
= & \underbrace{\sum_{j=1}^{4} \Delta P\left(A C \mid P E_{j}\right) P_{t}\left(F E_{j}\right)}_{\lambda}+\underbrace{\sum_{j=1}^{4} \Delta P(F E) P_{t-1}\left(A C \mid F E_{j}\right)}_{\eta}
\end{aligned}
$$

The term $\lambda$ measures the educational expansion which is independent of parental education. The second term $\eta$ measures the effect of higher schooling which is due to a better starting position, i.e. an increase in parental education. $P_{t}\left(F E_{j}\right)$ and $P_{t-1}\left(A C \mid F E_{j}\right)$ are the weights, respectively. Applying this decomposition to 
the results in Table 4, we find that the overall trend for females and males can be decomposed as follows

\begin{tabular}{|c|c|c|c|}
\hline & $\Delta P(A C)$ & $=$ Expansion & + Parental background \\
\hline Fem & 0.111 & 0.064 & 0.047 \\
\hline ales & 0.065 & 0.025 & 0.040 \\
\hline
\end{tabular}

What these numbers tell us is that for women, the fraction with an academic degree increased by 11 percentage points over the thirty year period. A 6.4 percentage point increase would have been observed even if the parental education had been already as favorable for the earlier cohort, as it eventually was for the latter. The remaining 4.7 percentage points (or 42 percent of the overall increase) is due to the improvement in the parental education. Thus, for women, the expansion effect was somewhat more important. The opposite is observed for men, where 62 percent of the increase in the fraction of academic degree holders can be attributed to the parental background effect.

While there was thus a substantial expansion effect for both men and women, it is a separate question to ask whether all education strata benefited equally from it. The same (average) expansion effect can in principle result from very different processes, for example one where convergence takes place, i.e. the academic degree rates increase faster for the low probability groups (i.e., those with less educated parents); one where all groups benefit equally; or even one that leads to increased polarization, because the increases are largest for those who have already a high probability of obtaining an academic degree.

This question can be directly addressed by looking at the component parts of the expansion effect, $P_{t}\left(A C \mid F E_{j}\right)-P_{t-1}\left(A C \mid F E_{j}\right)$ for $j=1, \ldots, 4$ in Table 4. For both men and women, the proportion of children with academic degree, conditional on the parent having an academic degree, did actually fall, thus certainly contributing to convergence.

The probability increased for all other three categories of father's education, although the pattern is somewhat checkered. All in all, the results suggest that the general expansion was combined with convergence in the probability of an academic degree between children of less and highly educated parents. Part of convergence was likely mechanical: if transition rates are already very high, as they approach the upper limit of one, growth is bound to be smaller than if transition rates are very low initially. Also, schooling institutions may have played a role in making education more equitable. There is an additional channel that we can analyze with our data, namely the role of financial constraints. The role of financial constraints may have diminished over time, as the rising income levels 
made education more affordable for parents of lower socio-economic background as well. This is explored in the next section.

\section{A Logit Model of Tertiary Education}

We know from the literature that children of financially constrained families have lower educational outcomes than children of richer families. ${ }^{10}$ Since less educated parents tend to have a higher incidence of "financial problems" than highly educated parents - a correlation confirmed in our data - the reason for convergence may be due to a decreasing incidence (or importance) of "financial problems". This channel will be tested in the next section using a multivariate logit analysis, where we also allow for separate effects of paternal and maternal education (as well as having siblings and living with both parents during childhood).

Table 5 shows the logit regression results separately by cohort and gender. Since the explanatory variables father's and mother's education are categorical, the estimated coefficients have to be interpreted relative to the omitted category, here the lowest educational outcome. The logit model is non-linear and the estimated coefficients do not have a direct interpretation as marginal effects. In the logit model, they estimate the change in the log-odds associated with a switch of the corresponding regressor from 0 to 1 . This interpretation is somewhat unintuitive, and therefore we show also, in a separate Table 6 , the predicted probability changes. In either case, the sign of the coefficient unambiguously relates to the sign of the log-odds and probability change respectively.

Thus, focusing on coefficients that are statistically significant, we can conclude from Table 5 that having a father with an academic degree, rather than a father with just compulsory schooling, has a positive ceteris paribus effect on the probability of an own academic degree for all groups. A mother with any tertiary degree has also a significant effect, as indeed having a mother with upper secondary degree. Whose education is then more important, that of the mother or that of the father? For women, the coefficient of mother: any tertiary is of about the same size as the coefficient father: academic. This means that the predicted probability of an academic degree would be about the same for a compulsory father/ tertiary mother person and for a compulsory mother/ academic father person. For men, this is not the case: the effect of the father's degree exceeds that of the mother's. If we consider the trade-off between compulsory and upper secondary

10 See for example: Chevalier and Lanot (2002), Ermisch and Francesconi (2001), Jenkins and SCHLuter (2004). 
Table 5: Logit Results for Probability of Academic Degree

\begin{tabular}{|c|c|c|c|c|}
\hline & \multicolumn{2}{|c|}{ Women } & \multicolumn{2}{|c|}{ Men } \\
\hline & $1934-1943$ & $1964-1973$ & $1934-1943$ & $1964-1973$ \\
\hline \multicolumn{5}{|l|}{ Highest degree of father } \\
\hline Upper secondary & $\begin{array}{c}0.297 \\
(0.387)\end{array}$ & $\begin{array}{c}0.133 \\
(0.218)\end{array}$ & $\begin{array}{c}0.600^{*} \\
(0.251)\end{array}$ & $\begin{array}{c}0.320 \\
(0.198)\end{array}$ \\
\hline Advanced vocational & $\begin{array}{c}0.609 \\
(0.493)\end{array}$ & $\begin{array}{c}0.314 \\
(0.319)\end{array}$ & $\begin{array}{c}0.059 \\
(0.459)\end{array}$ & $\begin{array}{c}0.540^{*} \\
(0.269)\end{array}$ \\
\hline Academic & $\begin{array}{l}2.588^{* *} \\
(0.437)\end{array}$ & $\begin{array}{l}1.496^{* *} \\
(0.262)\end{array}$ & $\begin{array}{c}2.133^{* *} \\
(0.360)\end{array}$ & $\begin{array}{c}1.518^{* *} \\
(0.249)\end{array}$ \\
\hline \multicolumn{5}{|l|}{ Highest degree of mother } \\
\hline Upper secondary & $\begin{array}{l}0.994^{* *} \\
(0.308)\end{array}$ & $\begin{array}{l}0.704^{* *} \\
(0.180)\end{array}$ & $\begin{array}{l}1.015^{* *} \\
(0.219)\end{array}$ & $\begin{array}{c}0.631^{\text {** }} \\
(0.150)\end{array}$ \\
\hline Any tertiary & $\begin{array}{c}2.248^{* *} \\
(0.566)\end{array}$ & $\begin{array}{l}1.445^{* *} \\
(0.295)\end{array}$ & $\begin{array}{c}0.848+ \\
(0.500)\end{array}$ & $\begin{array}{l}0.939^{* *} \\
(0.300)\end{array}$ \\
\hline Financial Problems & $\begin{array}{c}-0.432 \\
(0.295)\end{array}$ & $\begin{array}{r}-0.426^{*} \\
(0.212)\end{array}$ & $\begin{array}{c}-0.467^{*} \\
(0.210)\end{array}$ & $\begin{array}{c}-0.691^{* *} \\
(0.224)\end{array}$ \\
\hline Living with both parents & $\begin{array}{c}-0.253 \\
(0.411)\end{array}$ & $\begin{array}{c}0.510^{*} \\
(0.257)\end{array}$ & $\begin{array}{c}0.462 \\
(0.339)\end{array}$ & $\begin{array}{c}0.210 \\
(0.219)\end{array}$ \\
\hline Siblings & $\begin{array}{c}-0.538 \\
(0.384)\end{array}$ & $\begin{array}{c}0.197 \\
(0.218)\end{array}$ & $\begin{array}{c}-0.430+ \\
(0.261)\end{array}$ & $\begin{array}{c}-0.209 \\
(0.182)\end{array}$ \\
\hline Constant & $\begin{array}{c}-2.616 \\
(0.504)\end{array}$ & $\begin{array}{c}-2.893 \\
(0.322)\end{array}$ & $\begin{array}{c}-1.905 \\
(0.425)\end{array}$ & $\begin{array}{c}-1.559 \\
(0.279)\end{array}$ \\
\hline Observations & 801 & 1533 & 668 & 1238 \\
\hline Log Likelihood & -193.04 & -671.489 & -324.096 & -706.451 \\
\hline
\end{tabular}

Robust standard errors in parentheses

+ significant at $10 \%{ }^{*}$ significant at $5 \%$; ${ }^{* *}$ significant at $1 \%$

education, however, the situation is different: the mother's education matters more for men as well as for women. The evidence is thus somewhat mixed. Also note that there is evidence that the presence of financial problems during childhood reduces the probability of an academic degree. This effect is statistically significant in three out of four models. The family composition (having at least one sibling, living with both parents) seems to play less of a role. 
Table 6: Average Predicted Probability of an Academic Degree by Parental Background

\begin{tabular}{|c|c|c|c|c|}
\hline & \multicolumn{2}{|c|}{ Women } & \multicolumn{2}{|c|}{ Men } \\
\hline & $1934-1943$ & $1964-1973$ & $1934-1943$ & $1964-1973$ \\
\hline Baseline probability $\mathrm{P}(\mathrm{AC})$ & 0.09 & 0.20 & 0.26 & 0.32 \\
\hline $\mathrm{P}(\mathrm{AC} \mid$ father compulsory $)$ & $\begin{array}{c}0.05 \\
(0.02)\end{array}$ & $\begin{array}{c}0.14 \\
(0.02)\end{array}$ & $\begin{array}{c}0.16 \\
(0.03)\end{array}$ & $\begin{array}{c}0.23 \\
(0.03)\end{array}$ \\
\hline $\mathrm{P}(\mathrm{AC} \mid$ father academic $)$ & $\begin{array}{c}0.38 \\
(0.07)\end{array}$ & $\begin{array}{c}0.40 \\
(0.03)\end{array}$ & $\begin{array}{c}0.59 \\
(0.07)\end{array}$ & $\begin{array}{c}0.56 \\
(0.04)\end{array}$ \\
\hline Difference & $\begin{array}{c}0.33 \\
(0.07)\end{array}$ & $\begin{array}{c}0.26 \\
(0.04)\end{array}$ & $\begin{array}{c}0.43 \\
(0.06)\end{array}$ & $\begin{array}{c}0.33 \\
(0.05)\end{array}$ \\
\hline $\mathrm{P}(\mathrm{AC} \mid$ mother compulsory $)$ & $\begin{array}{c}0.06 \\
(0.01)\end{array}$ & $\begin{array}{c}0.13 \\
(0.01)\end{array}$ & $\begin{array}{c}0.20 \\
(0.02)\end{array}$ & $\begin{array}{c}0.25 \\
(0.02)\end{array}$ \\
\hline $\mathrm{P}(\mathrm{AC} \mid$ mother any tertiary $)$ & $\begin{array}{c}0.30 \\
(0.11)\end{array}$ & $\begin{array}{c}0.37 \\
(0.05)\end{array}$ & $\begin{array}{c}0.34 \\
(0.10)\end{array}$ & $\begin{array}{c}0.44 \\
(0.06)\end{array}$ \\
\hline Difference & $\begin{array}{c}0.24 \\
(0.11)\end{array}$ & $\begin{array}{c}0.24 \\
(0.05)\end{array}$ & $\begin{array}{c}0.14 \\
(0.10)\end{array}$ & $\begin{array}{c}0.19 \\
(0.06)\end{array}$ \\
\hline $\mathrm{P}(\mathrm{AC} \mid$ no financial problem $)$ & $\begin{array}{c}0.10 \\
(0.01)\end{array}$ & $\begin{array}{c}0.21 \\
(0.01)\end{array}$ & $\begin{array}{c}0.29 \\
(0.02)\end{array}$ & $\begin{array}{c}0.34 \\
(0.01)\end{array}$ \\
\hline $\mathrm{P}(\mathrm{AC} \mid$ financial problem $)$ & $\begin{array}{c}0.07 \\
(0.01)\end{array}$ & $\begin{array}{c}0.15 \\
(0.02)\end{array}$ & $\begin{array}{c}0.21 \\
(0.03)\end{array}$ & $\begin{array}{c}0.21 \\
(0.04)\end{array}$ \\
\hline Difference & $\begin{array}{l}-0.03 \\
(0.02)\end{array}$ & $\begin{array}{r}-0.06 \\
(0.03)\end{array}$ & $\begin{array}{c}-0.08 \\
(0.03)\end{array}$ & $\begin{array}{l}-0.13 \\
(0.04)\end{array}$ \\
\hline
\end{tabular}

Standard errors in parentheses are computed using the bootstrap method.

All other regressors are kept constant at their sample values.

The predicted probabilities of an academic degree with different parental background are summarized in Table 6 . These are average predicted probabilities. For example, when conditing on the father's education, we set the education level of the father to one of the four possibilities, for everyone, while keeping all other values at their observed sample values. We can then predict the probability of an academic training for each person, assuming that their had a father with that education, and average over these $n$ predictions.

The change in the average predicted probabilities can be interpreted as the ceteris paribus effect of the associated regressor that was changed, because all 
other variables are kept constant at their actual sample values. For example, we find that the ceteris paribus effect for women of having a father with academic degree relative to having a father with compulsory education, on the probability of having an academic degree herself, is a 33 percentage point increase for the earlier cohort, and a 26 percentage point increase for the later cohort. These percentage point changes, while still being substantial, are smaller than those found in Table 4 with respect to paternal education (47 and 40 percentage points, respectively).

This discrepancy is to be expected, since the results in Table 4 do not control for maternal education and financial situation. But due to assortative matching, educated fathers tend to be married to more educated mothers (which indirectly increase the probability of an academic degree of the child). Moreover, a higher education level reduces the incidence of financial problems during childhood (which indirectly increase the probability of an academic degree as well). Thus, the unadjusted analysis gives us the combined effect of all these factors on own educational achievement, which tends to be larger than the regression-adjusted results, that filters out the specific effect of paternal education.

The earlier conclusions on convergence hold up in this multivariate analysis: the gap in the proportion of children with academic degree between those with uneducated and those with educated fathers has decreased over the two cohorts for both men and women. There is no such convergence effect with respect to the mother's education, though. One possible reason may be the broad categorization "any tertiary degree" used for mothers, which introduces additional imprecision.

Finally, we see from Table 6, that the effect of "financial problems" is not only statistically significant, but also economically substantial: For the 64-73 cohort, the probability of an academic degree is lowered by a predicted 6 percentage points for women, and by 13 percentage for men, if we compare persons with financial problems with otherwise similar persons without. Interestingly also, the change in the "penalty" for financial problems over time, is negative, meaning that the adverse effect of financial problems during youth on the probability of obtaining a university degree actually increased over time. However, these double differences are not statistically significant, i.e., we cannot reject the null hypothesis of a constant effect. 


\section{Concluding Remarks}

We have analyzed trends in education, and its intergenerational transmission, in Switzerland. After a general overview, we have focused on the probability of obtaining a university degree for two birth cohorts (1934-1943 and 1964-1973), using data from the 1999-2004 waves of the Swiss Household Panel. As methods, we used both a descriptive decomposition technique and a multivariate logit analysis, where we controlled for paternal education, maternal education, financial situation, siblings, and single parenthood.

The single most important determinant of the probability of an academic degree is parental education. However, we also find that the conditional transition rates have somewhat converged over time, i.e., that the influence of parental education, while still substantial, has decreased. The main driving force behind the convergence, although not significant in a statistical sense, is an increased probability of obtaining a university degree for those individuals with less educated parents. Our decomposition analysis also revealed that the trend growth in participation in tertiary education is to a substantial part mechani$\mathrm{cal}$, in the sense, that for each successive generation, as parental education levels increase, the child outcomes will increase as well even if the transition rates remain unchanged.

While Switzerland seems to be moving in the direction of more equal education outcomes - i.e. outcomes less dependent on parental background - certainly a desirable feature of the education system for many, some may deplore that the changes are too modest and slow. For such a judgment to be made in an informed way, one would like to know how much the observed trends depend on opportunities as opposed to choice, and also how much the remaining inequalities are based on innate abilities, if any. Unfortunately, with the type of data we have access to, we feel that we cannot carry the analysis much further.

\section{References}

Angrist, Josh, Victor Lavy and Analia Schlosser (2006), "New Evidence on the Causal Link between the Quantity and Quality of Children", IZA Discussion Paper No. 2075.

Antonovics, Kate L. and Arthur S. Goldberger (2005), "Does Increasing Women's Schooling Raise the Schooling of the Next Generation? Comment", American Economic Review, 95, pp. 1738-1744. 
Bauer, Philipp and Regina T. Riphahn (2006a), "Education and its Intergenerational Transmission: Country of Origin-specific Evidence for Natives and Immigrants from Switzerland", Portuguese Economic Journal 5, pp. 89-110.

Bauer, Philipp and Regina T. Riphahn (2006b), "Timing of School Tracking as a Determinant of Intergenerational Transmission of Education", Economics Letters 91, pp. 90-97.

Behrman, Jere R. and Mark R. Rosenzweig (2002), "Does Increasing Women's Schooling Raise the Schooling of the Next Generation?”, American Economic Review, 92, pp. 323-334.

Black, Sandra E., Paul J. Devereux and KJell G. Salvanes (2005), "Why the Apple Doesn't Fall Far: Understanding Intergenerational Transmission of Human Capital", American Economic Review, 95, pp.437-449.

Cameron, Stephen and James Heckman (2001), "The Dynamics of Educational Attainment for Black, Hispanic, and White Males", Journal of Political Economy 109, pp. 455-499.

Chevalier, Arnaud and Gauthier Lanot (2002), "The Relative Effect of Family Characteristics and Financial Situation on Educational Achievement", Education Economics, 10, pp. 165-181.

Dustmann, Christian (2004), "Parental Background, Secondary School Track Choice, and Wages", Oxford Economic Papers, 56, pp. 209-230,

Ermisch, John and Marco Francesconi (2001), "Family Matters: Impacts of Family Background on Educational Attainments", Economica, 68, pp. 137-156.

Haveman, Robert and Barbara Wolfe (1995), "The Determinants of Children's Attainments: A Review of Methods and Findings", Journal of Economic Literature, 1995, 33, pp. 1829-1878.

Jenkins, Stephen P. and Christian Schluter (2004), "The Effect of Familiy Income During Childhood on Later-Life Attainment: Evidence from Germany", IZA Discussion Paper No. 604.

Schütz, Gabriela, Heinrich W. Ursprung, and Ludger Woessmann (2004), "Education Policy and Equality of Opportunity", CESifo Working Paper No. 1518.

Vellacott, Maja C. and Stefan C. Wolter (2004), Equity in the Swiss Education System: Dimensions, Causes and Policy Responses. National Report from Switzerland contributing to the OECD's review of "Equity in Education", SKBF, Aarau.

Woessmann, Ludger (2004), "How Equal are Educational Opportunities? Family Background and Student Achievement in Europe and the USA", CESifo Working Paper No. 1162. 